\title{
The real-life effectiveness of palivizumab for reducing hospital admissions for respiratory syncytial virus in infants residing in Nunavut
}

Anna Banerji MD MPH FRCPC ${ }^{1}$, Vladimir Panzov MD ${ }^{1}$, Michael Young MD FRCPC ${ }^{2}$, Bonita E Lee MD FRCPC MSC (Epi) ${ }^{3}$,

Muhammad Mamdani PharmD MA MPH ${ }^{1}$, B Louise Giles MD FRCPC ${ }^{4}$, Marguerite Dennis RN ${ }^{5}$,

Johanne Morel MD MPH', Danny Bisson BSc(Hons) MD CCFP7, Bosco A Paes MBBS FRCPC ${ }^{8}$,

Charles Hui MD FRCPC ${ }^{9}$, Jim Mahony PhD FAAM FCCM ${ }^{10}$

\begin{abstract}
A Banerji, V Panzov, M Young, et al. The real-life effectiveness of palivizumab for reducing hospital admissions for respiratory syncytial virus in infants residing in Nunavut. Can Respir J 2014;21(3):185-189.

BACKGROUND/OBJECTIVE: Nunavut has the highest hospitalization rates for respiratory syncytial virus (RSV) worldwide, with rates of 166 per 1000 live births per year $<1$ year of age. Palivizumab was implemented in Nunavut primarily for premature infants, or those with hemodynamically significant cardiac or chronic lung disease; however, the effectiveness of the program is unknown. The objective of the present multisite, hospital-based surveillance study was to estimate the effectiveness of palivizumab in infants $<6$ months of age in Nunavut for the 2009 and 2010 RSV seasons.

METHODS: Infants identified as palivizumab candidates who were $<6$ months of age were compared with all admissions for lower respiratory tract infection through multisite, hospital-based surveillance documenting the adequacy of palivizumab prophylaxis, admission for lower respiratory tract infection and the results of RSV testing. The OR for RSV admission in unprophylaxed infants was compared with those who were prophylaxed, and the effectiveness of palivizumab was estimated.

RESULTS: Within the study cohort $(n=101)$ during the two RSV seasons, five of the 10 eligible infants who did not receive adequate prophylaxis were admitted with RSV while two of the 91 infants $<6$ months of age eligible for palivizumab who were adequately prophylaxed were hospitalized with RSV (OR 22.3 [95\% CI 3.8 to 130]; $\mathrm{P}=0.0005$ ). The estimated effectiveness of palivizumab for the cohort was as high as $96 \%$. Eight eligible infants were missed by the program and did not receive prophylaxis. CONCLUSION: Palivizumab was highly effective in reducing hospitalizations due to RSV infection in Nunavut. Further efforts need to be made to ensure that all eligible infants are identified.
\end{abstract}

Key Words: Effectiveness; Inuit; Nunavut; Palivizumab; Respiratory syncytial virus

$\mathbf{R}$ espiratory syncytial virus (RSV) is the leading cause of lower res$\mathrm{R}_{\text {piratory tract infections (LRTIs) globally }(1,2) \text { and is the single }}$ most common reason for hospitalizations among infants $(1,3)$. While the development of a safe and effective RSV vaccine remains unrealized, in 1998, palivizumab (Synagis, MedImmune Inc, USA), a monoclonal antibody against RSV, was licensed for the prevention of hospitalization of children considered to be at high risk for severe RSV infection. In the initial multicentre, randomized placebo-controlled trial comparing premature infants $\leq 35$ weeks' gestational age with or without bronchopulmonary dysplasia, overall, there was a $55 \%$ reduction in RSV hospitalizations $(10.6 \%$ versus $4.8 \%$; $\mathrm{P}<0.001$ ) in the palivizumab arm compared with placebo, with a $78 \%$ reduction in RSV hospitalizations in premature infants without bronchopulmonary dysplasia ( $8.1 \%$ versus $1.8 \%$; $\mathrm{P}<0.001)$ (4).
L'efficacité du palivizumab en situation réelle pour réduire les hospitalisations causées par le virus respiratoire syncytial chez les nourrissons qui habitent au Nunavut

HISTORIQUE ET OBJECTIF : Le Nunavut présente le plus fort taux d'hospitalisations attribuables au virus respiratoire syncytial (VRS) de par le monde, correspondant à 166 cas sur 1000 naissances vivantes par année chez les moins d'un an. L'utilisation du palivizumaba été implantée au Nunavut, principalement pour les nourrissons prématurés ou ceux qui sont atteints d'une maladie pulmonaire chronique ou cardiaque significative sur le plan hémodynamique. Cependant, on ne connaît pas l'efficacité de ce programme. La présente étude de surveillance multihospitalière visait à évaluer l'efficacité du palivizumab chez les nourrissons de moins de six mois au Nunavut pendant les saisons du VRS de 2009 et 2010.

MÉTHODOLOGIE : Les chercheurs ont comparé les nourrissons qui étaient déterminés comme candidats au palivizumab et qui avaient moins de six mois à toutes les hospitalisations causées par une infection du système respiratoire inférieur par l'entremise d'une surveillance multihospitalière étayant le caractère pertinent de la prophylaxie au palivizumab, des hospitalisations attribuables à une infection du système respiratoire inférieur et des résultats des tests du VRS. Ils ont comparé le rapport de cotes d'hospitalisations attribuables au VRS chez les nourrissons sans prophylaxie à celui des nourrissons sous prophylaxie et évalué l'efficacité du palivizumab.

RÉSULTATS : Au sein de la cohorte à l'étude $(\mathrm{n}=101)$ pendant les deux saisons de VRS, cinq des dix nourrissons admissibles qui n'avaient pas reçu la prophylaxie pertinente ont été hospitalisés en raison d'un VRS tandis que deux des 91 nourrissons de moins de six mois admissibles au palivizumab qui avaient reçu une prophylaxie pertinente ont été hospitalisés pour la même raison (rapport de cotes 22,3 [95 \% IC 3,8 à 130]; P=0,0005). L'efficacité estimative du palivizumab dans la cohorte atteignait $96 \%$. Le programme a omis huit nourrissons admissibles, qui n'ont pas reçu de prophylaxie.

CONCLUSION : Le palivizumab réduisait le nombre d'hospitalisations causées par l'infection à VRS avec une grande efficacité au Nunavut. D'autres efforts s'imposent pour s'assurer de dépister tous les nourrissons admissibles.

Nunavut is Canada's largest federal territory and has one of the highest rates of hospitalization for RSV globally. RSV causes considerable morbidity in the Arctic regions (5-13) and in Inuit children. The annual rate of admission for RSV was 166 per 1000 live births in the first year of life on Baffin Island in 2001, before the use of palivizumab (5), which is the highest documented rate globally (14). Most of these admissions were in term infants without underlying risk factors (7). For the subset of infants $<6$ months of age residing in remote communities, the rates of RSV admissions ranged from 328 to 512 per 1000 infantyears (5), and $5.2 \%$ of the population born in remote communities on Baffin Island required mechanical ventilation in the first six months of life due to RSV infection (5). In addition to extremely high rates of RSV hospitalizations in Nunavut, severe complications and prolonged mechanical ventilation frequently result (6-9). Palivizumab was

${ }^{1}$ Li Ka Shing Knowledge Institute, St Michael's Hospital, Toronto, Ontario; ${ }^{2}$ IWK Children's Hospital, Halifax, Nova Scotia; ${ }^{3}$ Provincial Public Health

Laboratory, Edmonton Clinic Health Academy (ECHA), Edmonton, Alberta; ${ }^{4}$ Winnipeg Children's Hospital, Winnipeg, Manitoba; ${ }^{5}$ Sunnybrook

Health Sciences Centre, Toronto, Ontario; ${ }^{6}$ Montreal Children's Hospital, Montreal, Quebec; 7 JA Hildes Northern Medical Unit, Winnipeg,

Manitoba; ${ }^{8}$ Department of Pediatrics, McMaster University, Hamilton; ${ }^{9}$ Children's Hospital of Eastern Ontario, Ottawa; ${ }^{10}$ Regional Virology $\mathcal{E}^{2}$

Chlamydiology Laboratory, Department of Pathology and Molecular Medicine, McMaster University, St Joseph's Healthcare, Hamilton, Ontario

Correspondence and reprints: Dr Anna Banerji, Global and Indigenous Health, Continuing Professional Development, Faculty of Medicine, University of

Toronto, 650-500 University Avenue, Toronto, Ontario M5G 1V7. Telephone 416-978-8319, fax 416-971-2200,

e-mail anna.banerji@utoronto.ca 
licensed in Canada in 2002 and the Nunavut program was initiated in 2005. Due to the very high cost of this intervention, palivizumab has been restricted to populations traditionally considered to be at the highest risk for RSV disease, including all infants born up to 35 weeks' gestation, and those with significant cardiac or respiratory conditions $(4,15,16)$.

However, Nunavut presents a unique circumstance, where the extreme morbidity from RSV and the high costs of transporting infants to hospital $(5,9,17-20)$ results in a situation in which even prophylaxis of term Inuit infants in remote communities (without a hospital) was projected to result in cost savings (5). The Canadian Paediatric Society currently recommends that term Inuit infants $<6$ months of age at the start of the RSV season and residing in remote communities with a persistently high rate of RSV hospitalization be considered for palivizumab prophylaxis (21); however, this has not yet been implemented.

The effectiveness of palivizumab in Nunavut preterm infants has not been established and, currently, there are few published data regarding the use of palivizumab in Inuit or other Aboriginal infants. Introduction of palivizumab in the Yukon Kuskokwim Delta and southwest Alaska region in Alaska (USA) demonstrated a declining trend in RSV hospitalization in premature infants $(22,23)$ while rates remained constant in term infants. The purpose of the present prospective, observational study was to estimate the effectiveness of palivizumab in the population of Nunavut infants through hospitalbased surveillance of LRTIs over two consecutive RSV seasons.

\section{METHODS}

Nunavut is divided into three geographical regions: Kitikmeot (Western), Kivalliq (Central) and Qikiqtani (or Baffin) (Eastern), with estimated (2006 figures) populations of 5361, 8348 and 15,764, respectively, of whom nearly $85 \%$ are Inuit (24). The number of births in Nunavut in 2009 and 2010 were 812 and 835, respectively (25). The Qikiqtani General Hospital in Iqaluit is the only regional hospital in Nunavut and services most of the Qikiqtani region. Typically, infants who require tertiary care from this region are referred to the Children's Hospital of Eastern Ontario in Ottawa, Ontario. Infants from the Kitikmeot region are admitted to Stanton Regional Hospital in Yellowknife (Northwest Territories) and transferred to Stollery Children's Hospital (Edmonton, Alberta) if they require tertiary care, while infants from the Kivalliq region are admitted to Churchill Health Centre (Churchill Manitoba) or transferred to Children's Hospital of Winnipeg (Winnipeg, Manitoba) for tertiary care. All hospitals above were included in this surveillance.

In Nunavut, infants were eligible for palivizumab if they were $<6$ months of age at the beginning of the RSV season, with a gestational age of $<36$ weeks and/or had significant cardiac or respiratory disease (21). Eligible infants were identified by nurses in the communities, which was then verified and confirmed by the government of Nunavut (GN) (personal communication, Dr Geraldine Osborne). In Nunavut, the RSV season typically spans January through June, with peaks between March and June (26,27). The GN protocol for the 2009 and 2010 seasons included initiating palivizumab $15 \mathrm{mg} / \mathrm{kg} / \mathrm{dose}$ the week of December 15, followed by a second dose after three weeks and, subsequently, every four weeks until the end of the RSV season (personal communication, GN). The final dose was given during the week of June 22, for a maximum of seven doses, due to prolonged RSV seasons. For the purposes of the present study, the 2009 and 2010 RSV seasons were defined as January 1 to June 30 . The GN provided a data set of all identified palivizumab candidates, with the reasons for eligibility, timing and dosage of palivizumab received.

The present study was nested in a larger cohort surveillance of LRTI admissions in Arctic Canada over an 18-month period for infants $<1$ year of age $(6,7,17)$. The present study was observational because it would be unethical to offer placebo to infants at high risk for serious RSV infection. A hospital-based surveillance was conducted for all LRTI admissions in Nunavut regional and tertiary care centres for infants who were $<6$ months of age at the beginning of the 2009 or 2010 RSV seasons. Inclusion criteria included an infant who resided in Nunavut who was $<6$ months of age during the RSV season and met the GN eligibility criteria for palivizumab in 2009 and 2010. Exclusion criteria included any infant who was not tested for RSV by enzyme-linked immunoassay (EIA) or polymerase chain reaction (PCR).

Infants from the Kitikmeot and Kivalliq regions were prospectively enrolled while infants from the Qikiqtani region were retrospectively enrolled due to an unanticipated delay in obtaining administrative approval. In addition, a chart review at all sites of infants who were $<6$ months of age during the study period were reviewed to include missed cases. Data regarding gestational age and underlying cardiac or pulmonary disease that would meet the criteria for inclusion for palivizumab were collected. Infants identified in the surveillance study were cross-referenced against the GN palivizumab dataset over the 2009 and 2010 RSV seasons, by comparing date of birth, community, sex and risk factors.

Viral testing of nasopharyngeal aspirate for clinical purposes was performed at the Provincial Public Health Laboratory in Edmonton, Alberta, Cadham Provincial Laboratories in Winnipeg, Manitoba or at the Montreal Children's Hospital in Montreal, Quebec. In addition, some regional laboratories performed rapid RSV testing using EIA. To enhance viral diagnostics, residual nasopharyngeal aspirate collected from the majority of prospectively enrolled infants were frozen at $-70^{\circ} \mathrm{C}$, transferred in batches and processed at the Regional Virology Laboratory, McMaster University (Hamilton, Ontario) using the xTAG Respiratory Viral Panel (RVP) assay (Luminex Molecular Diagnostics, Canada), a multiplex PCR test for RSV and 19 other viruses.

Ethics approval was obtained from all hospitals. The study was administrated through the Applied Health Research Centre, St Michael's Hospital (Toronto, Ontario) and was licensed through the Nunavut Research Institute.

\section{Data analysis}

For all infants $<6$ months of age at the start of RSV season who were eligible for palivizumab, RSV hospitalization rates were compared for those who did and did not receive palivizumab as per protocol. The OR for RSV hospitalization in infants who received no/inadequate prophylaxis versus those who were adequately prophylaxed with palivizumab was calculated (Fisher's exact test [two-tailed; PASW Statistics version 17.0]). In addition, an estimation of the effectiveness of palivizumab over the two RSV seasons was calculated as follows (28):

(rate in eligible unprophylaxed group - rate in infants who received palivizumab) / (rate in eligible unprophylaxed group) $\times 100$

The palivizumab eligibility list provided by the GN was assumed to be a complete list of all eligible palivizumab candidates; however, on preliminary analysis, infants who met the criteria for prophylaxis but were not included on the GN list were identified. The effectiveness of palivizumab would be overestimated if there was a large number of infants eligible for palivizumab who were neither identified nor admitted with an LRTI. Because it was not practical to review the entire birth cohort of Nunavut to search for other eligible infants who were not admitted, a sensitivity analysis was conducted for the most extreme situation in which the maximum numbers of eligible infants were missed assuming the upper limit of potentially eligible infants was $8 \%$ of the birth population (based on a large study in the Qikiqtani region [19]), and that all additional eligible infants were not identified in the surveillance (neither admitted nor prophylaxed) were recalculated for the lowest limit of effectiveness. The primary data from a case control study conducted on Baffin Island, which enrolled $>50 \%$ of the birth cohort (19), $15 \%$ of the LRTI admissions and $4 \%$ of the controls were born $<36$ weeks' gestation. When adjusting for repeat admissions and then extrapolated to the entire population, the percentage of infants born before 36 weeks' gestation was estimated to not exceed $8 \%$. 


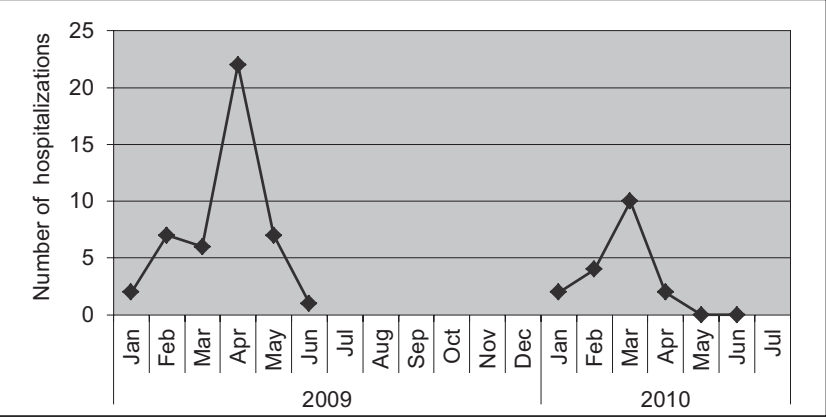

Figure 1) Respiratory syncytial virus-positive hospitalizations in infants $<6$ months of age in Nunavut

\section{RESULTS}

There were 210 admissions for LRTI in Nunavut for infants $<6$ months of age during the 18-month surveillance period; 65 of the 68 (96\%) RSV admissions occurred between January and June, affirming the delayed RSV season (Figure 1). Ninety-four infants were identified by the GN as palivizumab candidates ( $n=46$ in 2009, $n=48$ in 2010) and were cross-referenced with all LRTI admissions that occurred in the respective RSV seasons (Figure 2). One infant who was admitted with an LRTI was excluded due to the lack of viral testing. This study identified 26 hospital admissions of the 93 remaining infants. Ninety-one of these 93 infants received palivizumab according to the GN guidelines (Figure 2), and two were hospitalized with RSV and were considered to be palivizumab failures. Case 13 (Table 1) had RSV, rhinovirus/ enterovirus and influenza A subtype H1N1, and case 28 (Table 2) had RSV alone.

Two of the 93 infants (case 14 [Table 1] and case 29 [Table 2]) were admitted with RSV after incomplete or no palivizumab prophylaxis. Case 14 received palivizumab until March 2009 at a tertiary centre that was not continued on return to Nunavut; the infant was hospitalized with RSV 10 weeks after the final dose (ie, incomplete prophylaxis). Case 29 was only identified by the GN and prophylaxed as an eligible infant after an RSV admission. The present study also identified eight additional infants admitted with LRTIs who met the criteria for prophylaxis but were not on the GN eligibility list, yielding a total of 34 eligible infants admitted with LRTI (Figure 2, Tables 1 and 2). Three of these eight unprophylaxed infants were admitted with RSV.

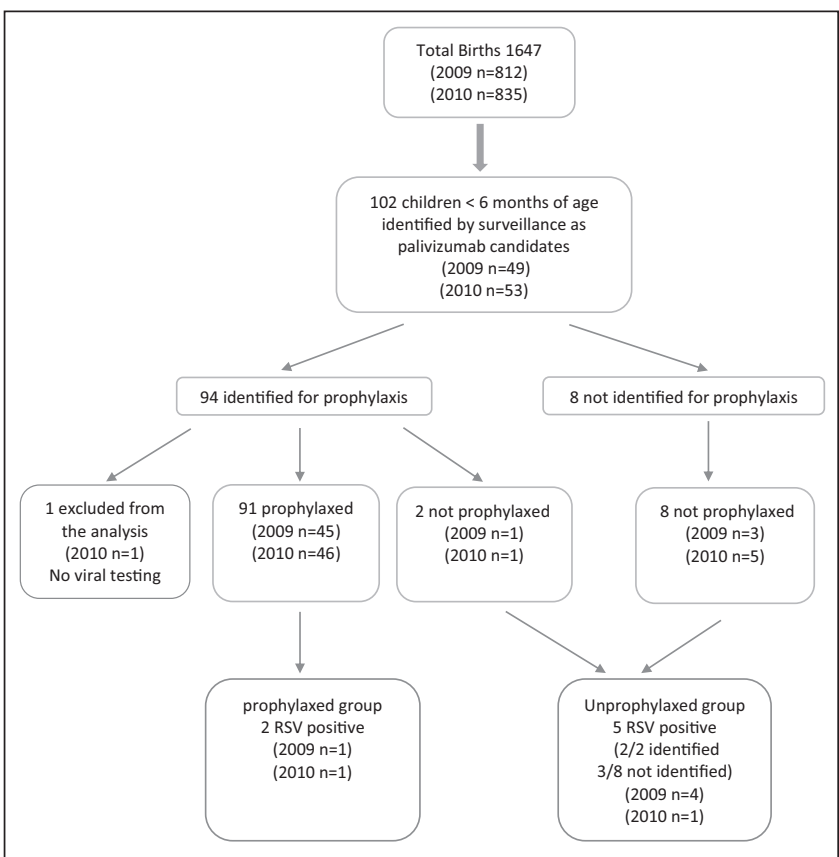

Figure 2) Palivizumab prophylaxis and respiratory syncytial virus (RSV) status for Inuit infants identified by surveillance as palivizumab candidates in Nunavut, admitted to hospital during the 2009 and 2010 RSV seasons

Within the study cohort $(n=101)$ during the two RSV seasons, two of the 91 infants $<6$ months of age eligible for palivizumab who were adequately prophylaxed were hospitalized for RSV, while five of the 10 eligible infants who did not receive adequate prophylaxis were admitted with RSV (Figure 2). The rate of RSV hospitalization for the infants not or inadequately prophylaxed with palivizumab (50\%) was significantly higher than the rate for the infants who had received RSV prophylaxis (2.2\%) OR 22.3 (95\% CI 3.8 to 130; $\mathrm{P}=0.0005)$. The estimated effectiveness of palivizumab for the cohort was $96 \%$.

A 'worst case scenario', in which $8 \%$ of the Nunavut population was eligible for palivizumab (approximately 65 infants per year) was assumed and that all infants not identified in the present study were missed. In

TABLE 1

Infants born July 1, 2008 to June 30, 2009 who were admitted during the 2009 respiratory syncytial virus (RSV) season and eligible for palivizumab in Nunavut

\begin{tabular}{|c|c|c|c|c|c|c|c|}
\hline Infant & $\begin{array}{c}\text { Age at } \\
\text { admission, months }\end{array}$ & $\begin{array}{c}\text { Gestational age, } \\
\text { weeks }\end{array}$ & Comorbidity & Identified by GN & $\begin{array}{c}\text { Received } \\
\text { palivizumab }\end{array}$ & Laboratory result & $\begin{array}{c}\text { Laboratory } \\
\text { testing method }\end{array}$ \\
\hline 1 & $<3$ & 29 & No & Yes & Yes & $\mathrm{RV} / \mathrm{EV}$, human coronavirus OC43 & PCR \\
\hline 2 & $<9$ & 29 & No & Yes & Yes & RV/EV & PCR \\
\hline 3 & $<6$ & 29 & No & Yes & Yes & Negative & EIA \\
\hline 4 & $<3$ & 35 & No & Yes & Yes & RV/EV & PCR \\
\hline 5 & $<12$ & 35 & Cardiac & Yes & Yes & Negative & EIA \\
\hline 6 & $<6$ & 34 & No & Yes & Yes & RV/EV , HMPV & PCR \\
\hline 7 & $<6$ & 33 & No & Yes & Yes & RV/EV & PCR \\
\hline 8 & $<3$ & 26 & No & Yes & Yes & RV/EV, adenovirus & PCR \\
\hline 9 & $<6$ & 26 & No & Yes & Yes & RV/EV & PCR \\
\hline 10 & $<3$ & 34 & No & Yes & Yes & RV/EV & PCR \\
\hline 11 & $<6$ & 32 & No & Yes & Yes & Negative & PCR \\
\hline 12 & $<6$ & 30 & No & Yes & Yes & Negative & EIA \\
\hline $13^{*}$ & $<6$ & 31 & Cardiac & Yes & Yes & RSV, RV/EV, influenza A (H1N1) & PCR \\
\hline $14^{\dagger}$ & $<6$ & 31 & No & Yes & No & RSV, parainfluenza & PCR \\
\hline 15 & $<3$ & 33 & No & No & No & RSV & PCR \\
\hline 16 & $<6$ & 31 & No & No & No & RSV & PCR \\
\hline 17 & $<3$ & 35 & No & No & No & RSV, Bordetella pertussis & PCR \\
\hline
\end{tabular}

*Vaccine failure; ${ }^{\dagger}$ Missed two doses of palivizumab before being admitted with RSV, counted as unvaccinated. EIA Enzyme-linked immunoassay; GN Government of Nunavut; HMPV Human metapneumovirus; PCR Polymerase chain reaction; RV/EV Rhinovirus/enterovirus 
TABLE 2

Infants born July 1, 2009 to June 30, 2010 who were admitted during the 2010 respiratory syncytial virus (RSV) season and eligible for palivizumab in Nunavut

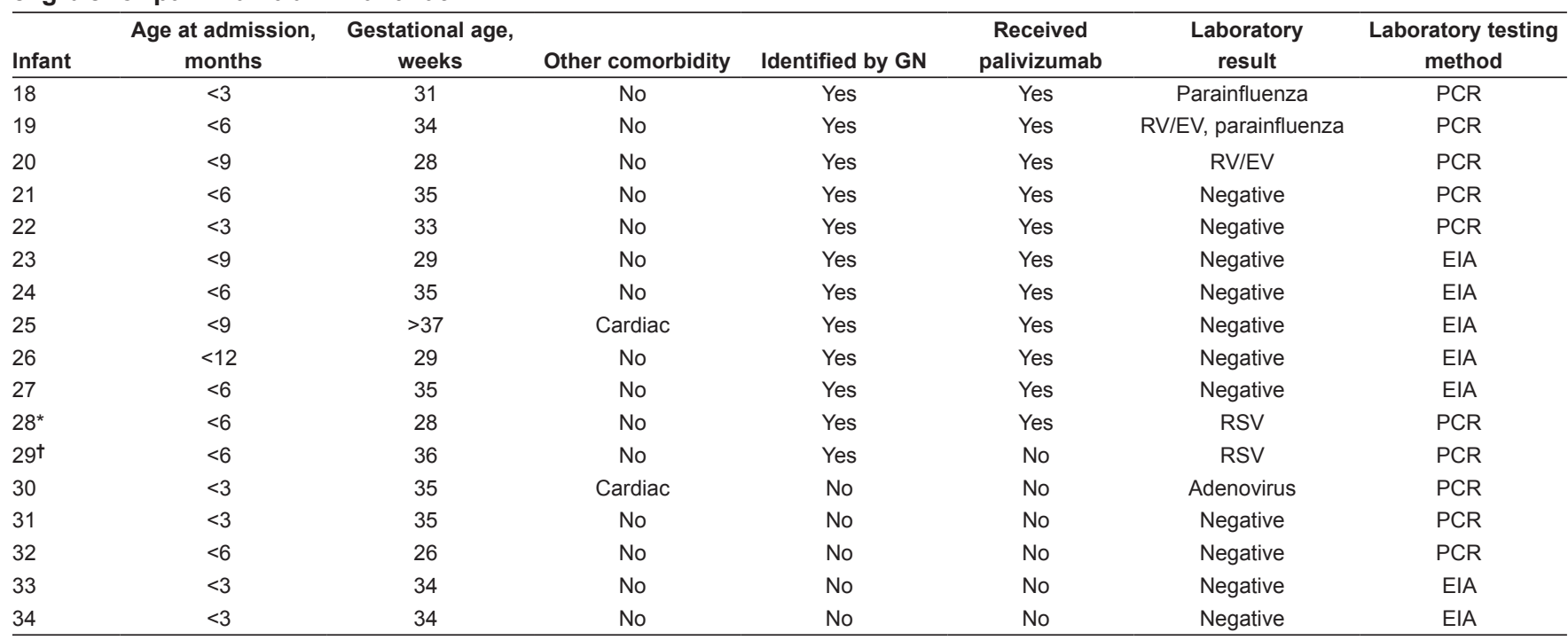

"Vaccine failure; †Only given palivizumab after hospital admission for RSV, classified as unvaccinated. EIA Enzyme-linked immunoassay; GN Government of Nunavut; PCR Polymerase chain reaction; RV/EV Rhinovirus/enterovirus

TABLE 3

Effectiveness of palivizumab in Nunavut 2009/2010 for infants $<6$ months of age who were eligible for respiratory syncytial virus (RSV) prohylaxis according to Government of Nunavut criteria*

\begin{tabular}{|c|c|c|c|c|c|c|c|c|}
\hline \multirow[b]{2}{*}{ RSV season } & \multirow{2}{*}{$\begin{array}{c}\text { Total } \\
\text { eligible, } \mathbf{n}\end{array}$} & \multicolumn{3}{|c|}{ Prophylaxed } & \multicolumn{3}{|c|}{ Unprophylaxed } & \multirow[b]{2}{*}{ Effectiveness $^{\dagger}$} \\
\hline & & $\mathbf{n}$ & RSV positive, $n$ & Attack rate & $\mathbf{n}$ & RSV positive, $n$ & Attack rate & \\
\hline 2009 & 49 & 45 & 1 & 0.021 & 4 & 4 & 1.0 & 0.979 \\
\hline 2010 & $52^{\ddagger}$ & 46 & 1 & 0.019 & 6 & 1 & 0.167 & 0.887 \\
\hline $2009 / 2010$ & 101 & 91 & 2 & 0.022 & 10 & 5 & 0.5 & 0.956 \\
\hline
\end{tabular}

${ }^{*}$ Eligible population born between January 1, 2008 and June 30, 2009, and between January 1, 2009 and June 30, $2010 ;$ †Palivizumab effectiveness = (attack rate in unprophylaxed - attack rate in prophylaxed) / attack rate in unprophylaxed; $\$ 53$ were prophylaxed but one was not tested for viruses and was excluded from the analysis

addition to the 49 and 53 infants identified by the GN in 2009 and 2010 , respectively, there would be 16 unidentified eligible infants in 2009 and 12 in 2010, resulting in a lower limit of palivizumab effectiveness of $83 \%([5 / 38-2 / 91] \div 5 / 38=83 \%)$ (Table 3$)$.

\section{DISCUSSION}

The results of the present study suggest that, in Nunavut, the use of palivizumab for high-risk infants was highly effective, with a failure rate of only $2 \%$. However, one of the two failures had coinfection with rhinovirus/enterovirus and influenza A (subtype pH1N1) and may not have truly been a palivizumab failure. The effectiveness of palivizumab is higher than that in any other subgroup of at-risk infants in the RSVIMpact study (4) or any Canadian subpopulation currently eligible for prophylaxis (21).

Although the GN list was initially assumed to be complete for eligible infants, we discovered through our analysis that some eligible infants were missed. It is of concern that at least eight preterm infants were never identified as being eligible for palivizumab and three were hospitalized with RSV. However, we believe that there are no systematic selection biases for the missed infants compared with the prophylaxed infants because they are serviced by different nursing stations. The unprophylaxed infants, however, did appear to be younger than the prophylaxed infants, which may be due to palivizumab providing protection in early infancy when the majority of admissions occur (19). Enhancing the awareness of nurses with regard to candidates who qualify for palivizumab may increase the capture of premature and other high-risk infants at birth. Because the RSV season in the Canadian Arctic is delayed compared with the rest of Canada $(26,27)$, it is vital that the local nursing stations identify infants who are transferred from southern hospitals, where the prophylaxis program has concluded, to avoid any gaps in prophylaxis.

Although the present study was limited by small numbers, the findings are relevant due to the significant impact of RSV in this population. In this cohort of infants, RSV was associated with severe complications, with a substantial number of transfers to tertiary hospitals for mechanical ventilation that was associated with prolonged intubation and secondary bacterial and fungal sepsis, among other complications $(6,7,17)$.

In addition to being extremely common, the costs incurred for RSV hospitalizations of Canadian Inuit infants are substantial (17). A recent budget impact analysis of a cohort on Baffin Island, based on palivizumab efficacy of $78 \%$, projected the number needed to treat to prevent one RSV hospitalization to be 3.9 for rural Inuit infants $<6$ months of age regardless of gestational age; universal palivizumab prophylaxis in the Baffin Island cohort living in remote communities was projected to result in cost savings (5). Our budget analysis of this cohort demonstrated a cost savings of $\$ 55,000$ per admission avoided in the Kitikmeot region in 2009 (29). The lack of effectiveness data from this cohort in the past has been a barrier to expanding the program to term Inuit infants.

Our data demonstrate that palivizumab was associated with a considerable decrease in RSV admissions in Inuit infants with the classic risk factors for severe disease. Because palivizumab is a monoclonal antibody, physiologically, it should be as effective in a term population who should be at a lower risk for severe RSV illness. Because palivizumab is very expensive, active surveillance of RSV in the North to monitor the start and end of the season would optimize its use. In addition, enhancement of public health measures to reduce the risk of RSV transmission is required (19). 


\section{Limitations}

The present study was limited by its small sample size due to the low birth rate in Nunavut. Additionally, a retrospective chart review was conducted in the Qikiqtani region where RSV testing had been performed at the discretion of the attending physician, which was, at times, suboptimal, and may have underestimated the true burden of RSV, especially because EIA has a sensitivity of $70 \%$ compared with PCR (30). Because this was an effectiveness study, it reflects real-life practice in the Arctic, where EIA is commonly performed for RSV detection instead of PCR; PCR testing as performed in our study represents enhanced testing. Because the present study was observational in nature, the number of and other variables for unprophylaxed infants could not be controlled. A study of future RSV seasons with enhanced and systematic identification of eligible infants would provide more information; however, multisite prospective surveillance in the remote Arctic communities can be logistically challenging and prohibitively expensive.

\section{CONCLUSION}

Our study demonstrates that RSV prophylaxis with palivizumab was highly effective in protecting high-risk Inuit infants from RSV hospitalization during the 2009 and 2010 RSV seasons. The major weakness in the current program was the lack of identification of all infants at high risk for RSV hospitalization. Efforts to enhance identification of these infants at birth should improve the impact of this program. The very high effectiveness of palivizumab in at-risk infants should be considered for the potential future expansion of prophylaxis to incorporate term infants in regions with high prevalence rates of RSV, as recommended by the Canadian Paediatric Society.

DEDICATION: The authors dedicate this study to the memory of Dr Michael Davis, one of the coinvestigators.

ACKNOWLEDGEMENTS: The authors thank Dr Geraldine Osborne and Department of Health and Social Services, Government of Nunavut. They also thank Dr Robert Holman, Centers for Disease Control and Prevention, Atlanta, Georgia, USA, for statistical review.

\section{REFERENCES}

1. Langley JM, Wang EE, Law BJ, et al. Economic evaluation of respiratory syncytial virus infection in Canadian children: A Pediatric Investigators Collaborative Network on Infections in Canada (PICNIC) study. J Pediatr 1997;131:113-7.

2. Mandell G, Bennett J, Dolin R, eds. Mandell, Douglas, and Bennett's Principles and Practice of Infectious Diseases, 7th edn. Philadelphia: Elsevier 2010.

3. Leader S, Kohlhase K. Recent trends in severe respiratory syncytial virus (RSV) among US infants, 1997 to 2000. J Pediatr 2003;143(5 Suppl):S127-32.

4. The IMpact-RSV Study Group. Palivizumab, a humanized respiratory syncytial virus monoclonal antibody, reduces hospitalization from respiratory syncytial virus infection in high-risk infants. The IMpact-RSV Study Group. Pediatrics 1998;102(3 Pt 1):531-7.

5. Banerji A, Lanctot KL, Paes BA, et al. Comparison of the cost of hospitalization for respiratory syncytial virus disease versus palivizumab prophylaxis in Canadian Inuit infants. Pediatr Infect Dis J 2009;28:702-6.

6. Banerji A, Young M, Northern RSV Surveillance Team, eds. Banerji A. Admission for Lower Respiratory Infections in Inuit Children in the Canadian Arctic: The Northern RSV Surveillance. 4th International Meeting on Indigenous Child Health.

Vancouver, March 5, 2011,

7. Banerji A, Young M, northern RSV Surveillance Team, eds. Is an ounce of palivizumab worth a pound of cure? Canadian Immunization Conference, Quebec City, December 6 to 8, 2010.

8. Banerji A. High rates of hospitalisation for bronchiolitis in Inuit children on Baffin Island. Int J Circumpolar Health 2001;60:375-9.
9. Banerji A, Bell A, Mills EL, et al. Lower respiratory tract infections in Inuit infants on Baffin Island. CMAJ 2001;164:1847-50.

10. Singleton RJ, Redding GJ, Lewis TC, et al. Sequelae of severe respiratory syncytial virus infection in infancy and early childhood among Alaska Native children. Pediatrics 2003;112:285-90.

11. Singleton R, Morris A, Redding G, et al. Bronchiectasis in Alaska Native children: Causes and clinical courses. Pediatr Pulmonol 2000;29:182-7.

12. Singleton RJ, Petersen KM, Berner JE, et al. Hospitalizations for respiratory syncytial virus infection in Alaska Native children. Pediatr Infect Dis J 1995;14:26-30.

13. Holman RC, Curns AT, Cheek JE, et al. Respiratory syncytial virus hospitalizations among American Indian and Alaska Native infants and the general United States infant population. Pediatrics 2004;114:e437-44.

14. Nair H, Nokes DJ, Gessner BD, et al. Global burden of acute lower respiratory infections due to respiratory syncytial virus in young children: A systematic review and meta-analysis. Lancet 2010;375:1545-55.

15. Meissner HC, Long SS. Revised indications for the use of palivizumab and respiratory syncytial virus immune globulin intravenous for the prevention of respiratory syncytial virus infections. Pediatrics 2003;112:1447-52.

16. Palivizumab and respiratory syncytial virus immune globulin intravenous for the prophylaxis of respiratory syncytial virus infection in high risk infants. Paediatr Child Health 1999;4:474-89.

17. Banerji A, Panzov V, Robinson J, Young M, Ng K, Mamdani M. The cost of lower respiratory tract infections hospital admissions in the Canadian Arctic. Int J Circumpolar Health 2013;72(21595).

18. Tam DY, Banerji A, Paes BA, Hui C, Tarride JE, Lanctot KL. The cost effectiveness of palivizumab in term Inuit infants in the Eastern Canadian Arctic. J Med Econ 2009;12:361-70.

19. Banerji A, Greenberg D, White LF, et al. Risk factors and viruses associated with hospitalization due to lower respiratory tract infections in Canadian Inuit children: A case-control study. Pediatr Infect Dis J 2009;28:697-701.

20. Creery D, Lyer P, Samson L, Coyle D, Osborne G, MacDonald A. Costs associated with infant bronchiolitis in the Baffin region of Nunavut. Int J Circumpolar Health 2005;64:38-45.

21. Robinson J. Preventing respiratory syncytial virus infections. Paediatr Child Health 2011;16:487-90.

22. Singleton RJ, Bruden D, Bulkow LR, Varney G, Butler JC. Decline in respiratory syncytial virus hospitalizations in a region with high hospitalization rates and prolonged season. Pediatr Infect Dis J 2006;25:1116-22.

23. Singleton R, Dooley L, Bruden D, Raelson S, Butler JC. Impact of palivizumab prophylaxis on respiratory syncytial virus hospitalizations in high risk Alaska Native infants. Pediatr Infect Dis J 2003;22:540-5.

24. Statistics Canada. Nunavut (Code 6205) (table). 2006 Community Profiles. 2006 Census. Statistics Canada Catalogue no. 92-591XWE. Ottawa2007 [cited 2011 November 22, 2011]. <www12. statcan.gc.ca/census-recensement/2006/dp-pd/prof/92-591/index. $\mathrm{cfm}$ ?Lang=E $>$ (Accessed January 2012).

25. Statistics Canada. Births, estimates, by province and territory Ottawa2011 [cited 2011 November 16, 2011]. <www40.statcan. gc.ca/101/cst01/demo04a-eng.htm> (Accessed January 2012).

26. Young M, Kandola K, Mitchell R, Leamon A. Hospital admission rates for lower respiratory tract infections in infants in the Northwest Territories and Kitikmeot region of Nunavut for 20002004. Paediatr Child Health 2007;12:563-6.

27. Singleton RJ, Bruden D, Bulkow LR. Respiratory syncytial virus season and hospitalizations in the Alaskan Yukon-Kuskokwim Delta. Pediatr Infectious Dis J 2007;26(11 Suppl):S46-50.

28. Orenstein WA, Bernier RH, Dondero TJ, et al. Field evaluation of vaccine efficacy. Bull World Health Organ 1985;63:1055-68.

29. Banerji A, Young M. The cost of lower respiratory tract Infections hospital admissions in the Canadian Arctic. 15th International Congress on Circumpolar Health. Fairbanks, Alaska, August 6, 2012.

30. Abels S, Nadal D, Stroehle A, Bossart W. Reliable detection of respiratory syncytial virus infection in children for adequate hospital infection control management. J Clin Microbiol 2001;39:3135-9. 


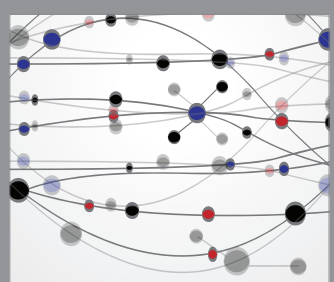

The Scientific World Journal
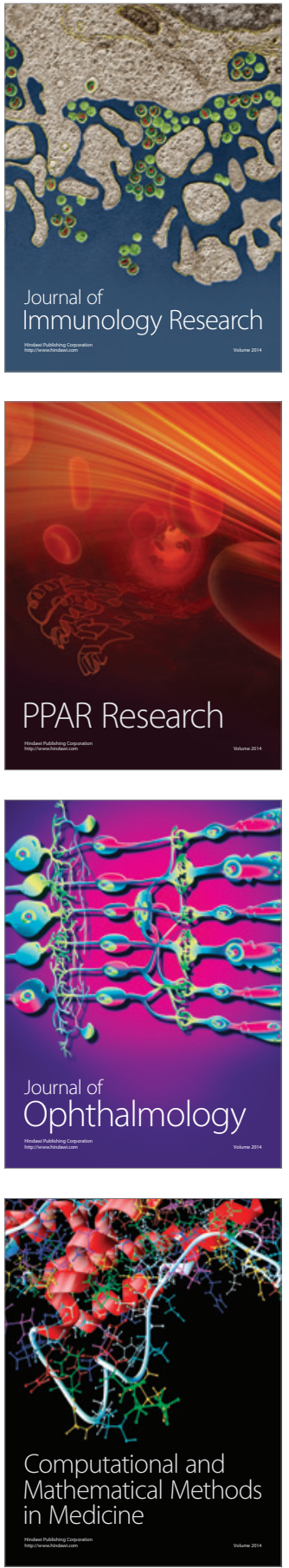

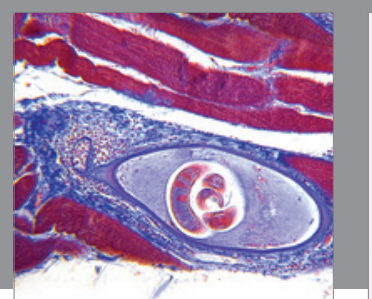

Gastroenterology Research and Practice

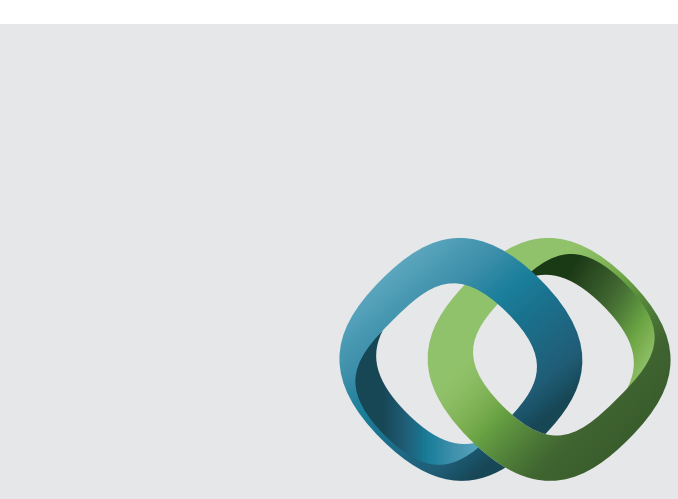

\section{Hindawi}

Submit your manuscripts at

http://www.hindawi.com
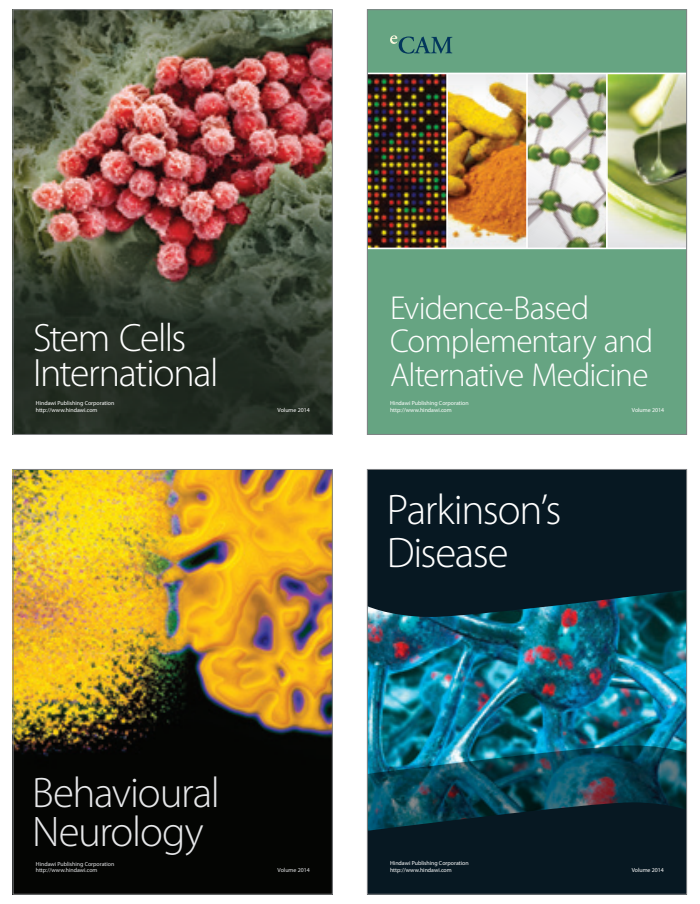
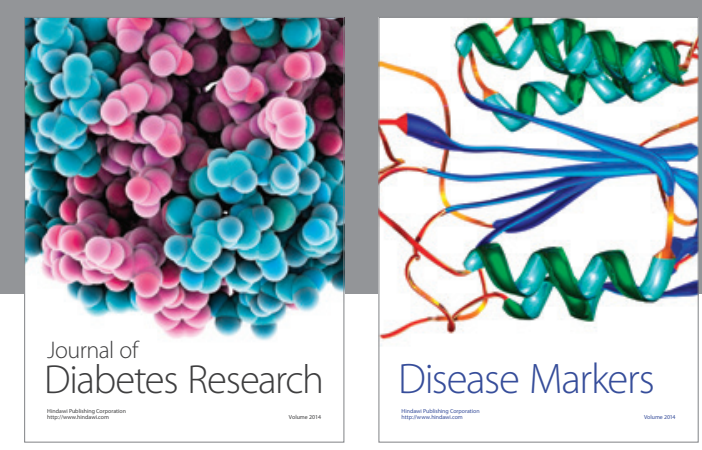

Disease Markers
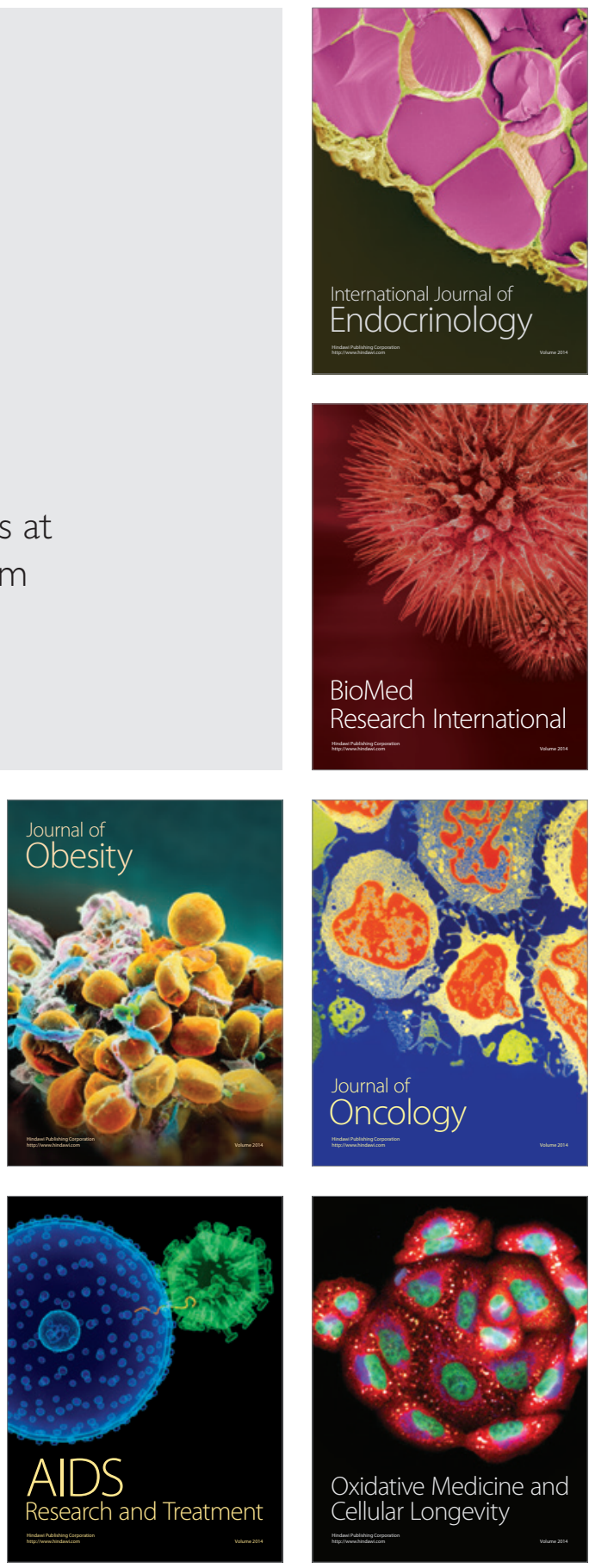